\title{
HUBUNGAN KUALITAS DAN KUANTITAS TIDUR DENGAN PRESTASI BELAJAR PADA MAHASISWA FAKULTAS KEDOKTERAN
}

\author{
Fenny*, Supriatmo** \\ * Mahasiswa Fakultas Kedokteran Universitas Sumatera Utara \\ ** Departemen Ilmu Kesehatan Anak, Fakultas Kedokteran Universitas Sumatera Utara
}

\begin{abstract}
Background: Sleeping is an essential need for every human beings in fulfilling their lives. There are two main components needed to put into consideration; they are sleeping quality and quantity. If the components are being distracted, it will cause impact on memory and concentration system. Consequently, it will cause the decline in academic achievements. The population who are at risk the most will be the collegestudents, especially medical students. Therefore, a research is conducted in order to determine relationship sleep quality and quantity with FK USU students' academic achievement's.

Method: This research, which is held from March to December 2015, uses analytic methods of case control study. In this study, there are 594 samples that correspond with inclusion and exclusion criterias; then, 150 subjects are being chosen for the case group and 150 subjects are also being chosen for the control group by using a simple random sampling technique. In addition, the research's datas are collected by using the PSQI and STQ questionnaires, then, they are analyzed by the SPSS computer program.

Results: A frequency distribution of the bad sleep quality and the less sleep quantity are the most in the USU's medical students with the respective figures of 185 respondents (61,7\%) and 163 respondents (54,3\%). The result of Chi Square analysis also shows that there is a significant relationship with the p value $<0,0001(p \leq 0,05)$. Besides, the result of multivariat analysis, which uses logistic regression, shows a final model formula is $\log p$ (bad academic achievement) $=-1,068+0,570$ (sleeping quality) $+1,303$ (sleeping quantity).
\end{abstract}

Conclusion: There is a relationship between the sleep quality and quantity with the FK USU students' academic achievement.

Keywords: sleep quality, sleep quantity, college student, academic achievement

\begin{abstract}
ABSTRAK
Latar belakang: Tidur merupakan salah satu kebutuhan dasar bagi setiap makhluk hidup untuk melangsungkan kehidupannya. Ada dua komponen utama yang perlu diperhatikan dalam tidur yaitu kualitas tidur dan kuantitas tidur. Apabila terjadi gangguan pada kedua komponen tersebut, maka akan menimbulkan dampak pada sistem memori dan konsentrasi. Akibatnya, akan menurunkan prestasi belajar seseorang. Adapun populasi yang paling berisiko mengalami gangguan tersebut adalah para mahasiswa terutama mahasiswa kedokteran. Oleh karena itu, penelitian ini dilaksanakan dengan tujuan untuk mengetahui hubungan kualitas dan kuantitas tidur dengan prestasi belajar pada mahasiswa FK USU.

Metode: Penelitian analitik dengan rancangan penelitian studi kasus kontrol yang berlangsung sejak bulan Maret hingga Desember 2015. Dalam penelitian ini, didapatkan 594 orang sampel yang sesuai dengan kriteria inklusi dan eksklusi, yang kemudian dipilih 150 orang untuk kelompok kasus dan 150 orang untuk kelompok kontrol dengan teknik simple random sampling. Adapun pengumpulan data penelitian dilakukan dengan menggunakan kuesioner PSQI dan STQ, yang kemudian dianalisis dengan program komputer SPSS.
\end{abstract}

korespondensi: fenny9944@gmail.com 
Hasil: Distribusi frekuensi kualitas tidur buruk dan kuantitas tidur kurang adalah yang terbanyak pada mahasiswa kedokteran USU dengan jumlah yang berurutan masing-masing sebanyak 185 orang $(61,7 \%)$ dan 163 orang (54,3\%). Hasil analisis Chi Square juga menunjukkan bahwa terdapat hubungan yang bermakna dengan nilai $p<0,0001(p \leq 0,05)$. Di samping itu, dari hasil analisis multivariat dengan uji regresi logistik, didapatkan persamaan model akhirnya berupa log $\mathrm{p}$ (prestasi belajar buruk) $=-1,068+0,570$ (kualitas tidur)+1,303(kuantitas tidur).

Kesimpulan: Terdapat hubungan antara kualitas dan kuantitas tidur dengan prestasi belajar pada mahasiswa FK USU.

Kata kunci: kualitas tidur, kuantitas tidur, mahasiswa, prestasi belajar

\section{PENDAHULUAN}

Setiap makhluk hidup dituntut untuk memenuhi kebutuhan dasarnya yang berguna untuk kelangsungan hidupnya. Salah satu kebutuhan dasar tersebut adalah kebutuhan tidur. ${ }^{1}$ Tidur merupakan suatu proses aktif, bukan sekedar hilangnya keadaan terjaga. Tingkat aktivitas otak keseluruhan tidak berkurang selama tidur. ${ }^{2}$ Di samping itu, ada dua faktor penting yang perlu diperhatikan dalam tidur sehingga seorang individu dapat memperoleh tidur yang cukup. Kedua faktor tersebut adalah kualitas dan kuantitas tidur. Kualitas tidur adalah suatu kondisi yang dijalani oleh seseorang sehingga mendapatkan kesegaran dan kebugaran saat terbangun dari tidurnya, sedangkan kuantitas tidur merupakan jumlah jam tidur normal yang diperlukan seseorang sesuai dengan kebutuhan tidurnya.

Di zaman era modern ini, aktivitas manusia semakin lama semakin meningkat sehingga perhatian terhadap aspek tidur yang cukup (secara kuantitas) dan berkualitas ini masih sangat kurang. Hal tersebut dibuktikan lewat survei indeks pola hidup sehat American International Assurance (AIA) pada tahun 2013 di Indonesia yang dilaksanakan oleh perusahaan riset global yaitu Taylor Nelson Sofrens (TNS). ${ }^{3}$ Survei tersebut menunjukkan bahwa masyarakat Indonesia yang ingin mendapatkan waktu tidur selama 7,8 jam ternyata hanya dapat merealisasikan 6,8 jam saja setiap harinya karena aktivitas mereka yang semakin lama semakin meningkat.

Adapun berbagai dampak yang dapat ditimbulkan oleh akibat kurangnya tidur pada seseorang. ${ }^{4}$ Dari berbagai dampak yang ditimbulkan tersebut, aspek utama yang paling dipengaruhi oleh akibat kurangnya tidur pada seseorang yaitu aspek memori dan konsentrasi. Kondisi ini banyak dijumpai pada anak sekolahan, mahasiswa, dan pekerja yang mempunyai jam terbang yang tinggi, dimana kelompok yang paling tinggi risikonya untuk terkena gangguan tidur adalah mahasiswa terutama para mahasiswa di fakultas kedokteran. Hal tersebut dibuktikan dari penelitianpenelitian sebelumnya yang dilaksanakan di berbagai negara dan didapatkan laporan bahwa tingkat distres psikologis, ansietas, dan depresi yang tinggi, terdapat pada mahasiswa fakultas kedokteran. ${ }^{5}$ Oleh karena itu, mahasiswa fakultas kedokteran rentan untuk mempunyai kualitas dan kuantitas tidur yang buruk.

Di samping itu, jika dikaitkan kualitas dan kuantitas tidur para mahasiswa dengan prestasi belajarnya maka berdasarkan penelitian-pene-litian sebelumnya, dilaporkan bahwa mahasiswa dengan siklus tidurbangun yang tidak teratur dan mempunyai jam tidur yang kurang menunjukkan nilai akademik yang lebih rendah. Penelitian-penelitian tersebut sejalan dengan penelitian Eliasson \& Lettieri, dimana mahasiswa dengan nilai yang lebih baik mempunyai hubungan yang signifikan dengan siklus tidur yang lebih awal dan bangun yang lebih awal. ${ }^{6}$

Oleh karena kebutuhan tidur sangat mem-pengaruhi berbagai fungsi tubuh seseorang terutama dalam hal konsolidasi memori yang pada akhirnya akan berpengaruh pada prestasi belajar seseorang, maka peneliti tertarik untuk melakukan penelitian lebih lanjut mengenai hubungan antara kualitas dan kuantitas tidur dengan prestasi belajar pada mahasiswa fakultas kedokteran yang dilakukan di 
Fakultas Kedokteran Universitas Sumatera Utara (USU) Medan. Adapun tujuan dari penelitian ini yaitu untuk mengetahui bagaimana hubungan kualitas dan kuantitas tidur dengan prestasi belajar pada mahasiswa FK USU angkatan 2013 dan 2014.

\section{METODE}

Jenis penelitian yang digunakan adalah observasional analitik dengan desain penelitiannya adalah case control study (studi kasus kontrol). Penelitian ini dilakukan di Fakultas Kedoteran USU Medan dengan waktu penelitiannya yang berlangsung sejak bulan Maret 2015 hingga Desember 2015.

Adapun populasi pada penelitian ini adalah seluruh mahasiswa Fakultas Kedokteran USU Medan angkatan 2013 dan 2014 yang berjumlah sekitar 685 orang. Dari 685 orang tersebut, dihitung besar sampel yang diperlukan dengan menggunakan rumus perhitungan sampel untuk analisis regresi logistik $^{7}$ dan didapatkan bahwa besar sampel yang perlu diambil sebanyak 300 orang (150 orang untuk kelompok kasus dan 150 orang untuk kelompok kontrol).

Di samping itu, sampel penelitian tersebut dipilih dengan menggunakan teknik probability sampling dengan jenis pengambilan sampel secara acak sederhana (simple random sampling). Adapun kriteria inklusi pada penelitian ini adalah seluruh mahasiswa Fakultas Kedokteran USU angkatan 2013 dan 2014 (berusia 17-25 tahun) yang masih aktif mengikuti perkuliahan dan memiliki prestasi buruk (kelompok kasus) serta memiliki prestasi baik (kelompok kontrol), sedangkan kriteria eksklusinya adalah sampel penelitian mengkonsumsi obat-obatan atau menderita penyakit tertentu atau mempunyai riwayat penyakit tertentu yang dapat mempengaruhi proses tidurnya dan sampel penelitian tidak mengisi kuesioner secara lengkap atau tidak datang pada saat diadakan pengambilan data responden.
Data yang digunakan pada penelitian ini berupa data primer yang diperoleh melalui pengisian kuesioner PSQI (kualitas tidur) dan STQ (kuantitas tidur), yang dimana pertanyaan-pertanyaan dalam kedua kuesioner tersebut sudah valid dan reliabel. Selain itu, juga digunakan data sekunder berupa data mengenai jumlah mahasiswa angkatan 2013 dan 2014 yang dapat diperoleh dari bagian pendidikan Fakultas Kedokteran USU dan data mengenai Indeks Prestasi Kumulatif (IPK) yang dapat diperoleh dari Kartu Hasil Studi (KHS) semester genap tahun ajaran 2014/2015 pada masing-masing mahasiswa.

Data-data yang diperoleh tersebut kemudian diolah dengan menggunakan progam komputer SPSS (Statistical Product and Service Solution) dan disajikan dalam bentuk tabel dan disertai narasi. Analisis data dalam penelitian ini dilakukan secara univariat dengan menggunakan bentuk analisis deskriptif, secara bivariat dengan menggunakan uji Chi Square, dan secara multivariat dengan menggunakan uji regresi logistik.

\section{HASIL DAN PEMBAHASAN}

Penelitian ini telah diadakan di Fakultas Kedokteran Universitas Sumatera Utara (USU) yang berlokasi di Jalan Dr. Mansyur No. 5 Medan, Kelurahan Padang Bulan, Kecamatan Medan Baru, Provinsi Sumatera Utara, Indonesia. Di samping itu, penelitian ini mengambil 300 orang (terdiri dari 150 orang untuk kelompok kasus dan 150 orang untuk kelompok kontrol) mahasiswa Fakultas Kedokteran USU yang berasal dari angkatan 2013 dan 2014 untuk dijadikan sampel penelitian.

Adapun hasil penelitiannya adalah yang pertama, hasil analisis univariat yang dapat dilihat pada Tabel 1 dan Tabel 2. 
Tabel 1. Distribusi Frekuensi Gambaran Karakteristik Sampel Penelitian

\section{Gambaran Karakteristik Sampel}

Frekuensi (orang)

Persentase (\%)

Usia (tahun)

17

18

19

20

21

22

23

24

25

Jenis Kelamin

Laki-laki

Perempuan

Angkatan

2013

2014
8

38

120

92

23

14

2

1

2

118

182

165

135
2,7

12,7

40,0

30,7

7,7

4,7

0,7

0,3

0,7

39,3

60,7

55,0

45,0
Pada Tabel 1 tersebut, terlihat bahwa pada distribusi frekuensi gambaran karakteristik sampel, sampel penelitian paling banyak berusia 19 tahun yaitu dengan jumlah sebanyak 120 orang (40\%). Kelompok usia 19 tahun lebih dominan dalam penelitian ini karena sampel penelitian ini diambil dari angkatan 2013 dan 2014, dimana usia ideal untuk seseorang yang duduk di angkatan tersebut adalah sekitar 19 tahun.

Untuk gambaran karakteristik jenis kelamin, terlihat bahwa jenis kelamin terbanyak pada penelitian ini adalah jenis kelamin perempuan dengan jumlah sebanyak 182 orang (60,7\%). Jenis kelamin perempuan lebih dominan dalam penelitian ini karena pada angkatan 2013 dan 2014, mahasiswanya lebih banyak yang berjenis kelamin perempuan daripada yang berjenis kelamin laki-laki. Kemudian, untuk gambaran karakteristik angkatan, dapat terlihat bahwa angkatan terbanyak dalam penelitian ini adalah angkatan 2013 dengan jumlahnya sebanyak 165 orang (55\%). Angkatan 2013 lebih banyak dalam penelitian ini karena berdasarkan perbandingan jumlah mahasiswa pada angkatan 2013 dengan 2014, jumlah mahasiswa pada angkatan 2013 lebih banyak daripada jumlah mahasiswa pada angkatan 2014. 
Tabel 2. Distribusi Frekuensi Variabel-Variabel Penelitian

\begin{tabular}{ccc}
\hline Variabel Penelitian & Frekuensi (orang) & Persentase (\%) \\
\hline Kualitas Tidur & & \\
Buruk & 185 & 61,7 \\
Baik & 115 & 38,3 \\
Kuantitas Tidur & & \\
Kurang & 163 & 54,3 \\
Cukup & 137 & 45,7 \\
Prestasi Belajar & & \\
Buruk & 150 & 50,0 \\
Baik & 150 & 50,0 \\
\hline
\end{tabular}

Selain itu, pada Tabel 2 tersebut, terlihat bahwa untuk variabel kualitas tidur, sampel penelitian paling banyak memiliki kualitas tidur buruk dengan jumlah yang mencapai 185 orang (61,7\%). Hasil distribusi frekuensi variabel kualitas tidur di dalam penelitian ini sejalan dengan hasil penelitian yang dilakukan oleh Putra dan Angkat, dimana didapatkan hasil bahwa sampel penelitian mereka juga lebih dominan memiliki kualitas tidur buruk daripada kualitas tidur baik. ${ }^{8,9}$ Beberapa penelitian tersebut termasuk penelitian ini membuktikan bahwa kualitas tidur pada usia masa sekolah dan masa perkuliahan cenderung lebih buruk mungkin disebabkan oleh berbagai faktor eksternal yang dapat menyebabkan supresi dari pengeluaran melatonin yang pada akhirnya akan dapat menyebabkan gangguan tidur.

Untuk variabel kuantitas tidur, didapatkan bahwa sampel penelitian paling banyak memiliki kuantitas tidur yang kurang dengan jumlah sebanyak 163 orang $(54,3 \%)$. Hasil ini sejalan dengan penelitian yang dilakukan oleh Fridayana $^{10}$ dimana hasil penelitiannya juga menunjukkan bahwa sampel penelitiannya yang juga merupakan mahasiswa kedokteran, mayoritasnya mempunyai kuantitas tidur yang kurang dengan jumlah yang mencapai 89 orang $(70,6 \%)$. Kurangnya kuantitas tidur pada mahasiswa terutama mahasiswa kedokteran mungkin disebabkan oleh aktivitas perkuliahan mereka yang padat. ${ }^{11}$

Di samping itu, untuk variabel prestasi belajar, setengah sampel penelitian memiliki prestasi belajar yang buruk dan setengahnya lagi memiliki prestasi belajar yang baik. Didapatkan hasil seperti ini karena memang dari awal direncanakan untuk mengambil 150 orang sampel yang berprestasi belajar buruk dan 150 orang sampel yang berprestasi belajar baik untuk dijadikan kelompok kasus dan kelompok kontrol.

Selanjutnya, yang kedua, hasil analisis bivariat dengan uji Chi Square yang dapat dilihat pada Tabel 3 dan 4.

Tabel 3. Hubungan Antara Kualitas Tidur dengan Prestasi Belajar pada Sampel Penelitian

\begin{tabular}{|c|c|c|c|c|c|}
\hline \multirow{2}{*}{$\begin{array}{c}\text { Kualitas } \\
\text { Tidur }\end{array}$} & \multicolumn{2}{|c|}{ Prestasi Belajar } & \multirow{2}{*}{ Total } & \multirow{2}{*}{ p-Value } & \multirow{2}{*}{$\begin{array}{c}\text { OR } \\
\text { (IK 95\%) }\end{array}$} \\
\hline & Buruk & Bai & & & \\
\hline Buruk & $\begin{array}{c}110 \\
(73,3 \%)\end{array}$ & $\begin{array}{c}75 \\
(50,0 \%)\end{array}$ & $\begin{array}{c}185 \\
(61,7 \%)\end{array}$ & \multirow{3}{*}{$<0,0001$} & \multirow{3}{*}{$\begin{array}{c}2,75 \\
(1,696 ; 4,458)\end{array}$} \\
\hline Baik & $\begin{array}{c}40 \\
(26,7 \%) \\
\end{array}$ & $\begin{array}{c}75 \\
(50,0 \%) \\
\end{array}$ & $\begin{array}{c}115 \\
(38,3 \%) \\
\end{array}$ & & \\
\hline Total & $\begin{array}{c}150 \\
(100,0 \%)\end{array}$ & $\begin{array}{c}150 \\
(100,0 \%)\end{array}$ & $\begin{array}{c}300 \\
(100,0 \%)\end{array}$ & & \\
\hline
\end{tabular}


Tabel 4. Hubungan Antara Kuantitas Tidur dengan Prestasi Belajar pada Sampel Penelitian

\begin{tabular}{cccccc} 
Kuantitas & \multicolumn{2}{c}{ Prestasi Belajar } & Total & p-Value & $\begin{array}{c}\text { OR } \\
\text { Tidu }\end{array}$ \\
\cline { 2 - 4 } Kurang & Buruk & Baik & & & \\
& 108 & 55 & 163 & & \\
\multirow{2}{*}{ Cukup } & $(72,0 \%)$ & $(36,7 \%)$ & $(54,3 \%)$ & & \\
& 42 & 95 & 137 & & $<, 442$ \\
Total & $(28,0 \%)$ & $(63,3 \%)$ & $(45,7 \%)$ & & $(2,729 ; 7,229)$ \\
& 150 & 150 & 300 & & \\
\hline
\end{tabular}

Dari kedua tabel tersebut, dapat disimpulkan bahwa terdapat hubungan yang signifikan antara kualitas tidur dan kuantitas tidur dengan prestasi belajar, dengan nilai $p$ pada masing-masing analisis sebesar <0,0001 (nilai $p \leq 0,05$ ). Untuk hasil analisis kualitas tidur, hasilnya sejalan dengan penelitian yang dilakukan oleh beberapa peneliti lainnya. ${ }^{10,12,13}$ Dalam penelitian mereka, juga didapatkan hasil berupa terdapat hubungan yang signifikan antara kualitas tidur dengan prestasi belajar. Selain itu, dari penelitian-penelitian tersebut, juga diketahui bahwa tidur memang sangat berperan penting dalam mengkonsolidasi memori dan pembelajaran. Oleh karena itu, jika kualitas tidur baik, maka konsolidasi memori yang terjadi saat tidur juga akan lebih maksimal sehingga akan mendapatkan prestasi belajar yang lebih baik.

Hal yang sama juga terjadi pada hasil analisis kuantitas tidur, yang dimana hasilnya juga sejalan dengan penelitian Eliasson \& Lettieri. ${ }^{6}$ Dalam penelitiannya, dia menyatakan bahwa mahasiswa yang kekurangan tidur (memiliki kuantitas tidur yang kurang) akan merasa mengantuk di siang hari, merasa lelah, dan mempengaruhi suasana hati $(\mathrm{mood})$ sehingga pada akhirnya akan membuat penurunan pada prestasi belajarnya.

Yang terakhir adalah hasil analisis multivariat dengan uji regresi logistik yang dapat dilihat pada Tabel 5.

Tabel 5. Hasil Analisis Regresi Logistik Ganda dari Variabel-Variabel Independen Penelitian

\begin{tabular}{cccccc} 
Variabel Independen & B & $\operatorname{Exp}(\mathbf{B})$ & SE & p-Wald & IK 95\% \\
\hline Kualitas Tidur & 0,570 & 1,769 & 0,270 & 0,035 & 1,$041 ; 3,005$ \\
Kuantitas Tidur & 1,303 & 3,681 & 0,263 & $<0,0001$ & 2,$200 ; 6,159$ \\
Konstanta & $-1,068$ & 0,344 & 0,226 & $<0,0001$ & - \\
\hline -2 Log Likelihood $=372,864$ & & & & p-Value $=<0,0001$
\end{tabular}

Pada Tabel 5 tersebut, terlihat bahwa kedua variabel independen yaitu variabel kualitas tidur dan variabel kuantitas tidur terbukti merupakan variabel yang berpengaruh terhadap prestasi belajar sehingga persamaan akhir model regresi logistik yang paling baik dan sederhana dalam menggambarkan hubungan antara variabel prestasi belajar dengan kedua variabel independen adalah log $\mathrm{p}$ (prestasi belajar buruk $)=-1,068+0,570($ kualitas tidur $)+$ 1,303 (kuantitas tidur).

Hasil penelitian multivariat ini sejalan dengan hasil penelitian yang dilakukan oleh Killgore, et al. ${ }^{14}$, yang dimana dalam penelitiannya tersebut ditunjukkan bahwa penurunan pada kualitas tidur dan kuantitas tidur akan berdampak pada sistem neurobehavioral, neurocognitive, dan psychomotoric sehingga akibatnya 
dapat berupa menurunnya konsentrasi, daya ingat, kemampuan mengatasi masalah dan pengambilan keputusan, berpikir kritis serta menurunnya prestasi akademik. Dengan demikian, dari hasil penelitian ini dan dari penelitian-penelitian sebelumnya dapat ditarik suatu kesimpulan bahwa kualitas dan kuantitas tidur seseorang sangat mempengaruhi prestasi belajarnya.

\section{KESIMPULAN}

Berdasarkan hasil analisis dari data yang diperoleh dapat disimpulkan bahwa terdapat hubungan yang signifikan atau bermakna antara kualitas tidur dan kuantitas tidur dengan prestasi belajar pada mahasiswa FK USU angkatan 2013 dan 2014 dengan nilai $p<0,0001$ (nilai $p \leq 0,05$ ). Pada penelitian ini, sampel yang didapatkan paling banyak berusia 19 tahun dengan jumlah sebanyak 120 orang (20\%), paling banyak yang berjenis kelamin perempuan dengan jumlah sebanyak 182 orang $(60,7 \%)$, dan paling banyak yang berasal dari angkatan 2013 dengan jumlah sebanyak 165 orang (55\%).

Distribusi frekuensi kualitas tidur terbanyak adalah kualitas tidur buruk dengan jumlah sebanyak 185 orang $(61,7 \%)$ dan untuk kuantitas tidur, paling banyak adalah kuantitas tidur kurang dengan jumlah mencapai 163 orang (54,3\%). Persamaan model akhir yang didapat dari hasil uji regresi logistik pada analisis multivariat adalah $\log \mathrm{p}$ (prestasi belajar buruk) $=-1,068+0,570$ (kualitas tidur $)+$ 1,303(kuantitas tidur).

\section{SARAN}

Dari seluruh proses dalam menyelesaikan penelitian ini, maka dapat diungkapkan beberapa saran yang mungkin dapat bermanfaat bagi semua pihak yang berperan dalam penelitian ini. Adapun saran tersebut yaitu bagi mahasiswa dan bagi masyarakat/ pembaca agar lebih memperhatikan kualitas dan kuantitas tidurnya. Kemudian, bagi peneliti selanjutnya, disarankan agar menggunakan sampel yang lebih besar supaya mendapatkan hasil yang lebih representatif dan disarankan menggunakan instrumen penelitian yang lebih akurat dan objektif dalam menilai kualitas dan kuantitas tidur seseorang.

\section{DAFTAR PUSTAKA}

1. Purnama PP. Hubungan tingkatan kecemasan dan gangguan pola tidur pada pasien pertama kali dirawat inap di ruang perawatan umum Rumah Sakit Pusat Angkatan Darat Gatot Subroto Jakarta. Jakarta; 2009.

2. Sherwood L. Susunan saraf pusat. Dalam: Yesdelita N, editor. Fisiologi manusia: dari sel ke sistem. Ed. 6. Jakarta: EGC; 2011.

3. Taylor Nelson Sofrens (TNS). Survei indeks pola hidup sehat American International Assurance (AIA). Indonesia; 2013.

4. Purwanto S. Mengatasi insomnia dengan terapi relaksasi, Universitas Muhammadiyah. Jurnal Kesehatan. 2008;2.

5. Frank E, Carrera JS, Elon L, Hertzberg VS. Basic demographics, health practices and health status of US medical students. Am J Prev Med. 2006;31(6):499. 505.

6. Eliasson AH, Lettieri CJ. Early to bed, early to rise! sleep habits and academic performance in college students. Sleep Breath. 2010;14(1):71-5.

7. Dahlan MS. Besar sampel dan cara pengambilan sampel dalam penelitian kedokteran dan kesehatan. Ed. 3. Jakarta: Salemba Medika; 2012.

8. Putra PB. Hubungan antara kualitas tidur dengan inteligensia pada siswa kelas X SMA Santo Thomas 2. Medan: Fakultas Kedokteran Universitas Sumatera Utara; 2011.

9. Angkat DNS. Hubungan antara kualitas tidur dengan tekanan darah pada remaja usia 15-17 tahun di SMA Negeri 1 Tanjung Morawa. Medan: SMA Negeri 1 Tanjung Morawa; 2009.

10. Fridayana. Hubungan antara kualitas dan kuantitas tidur dengan nilai modul pada mahasiswa kedokteran praklinik Universitas Tanjungpura. Pontianak: Program Studi Pendidikan Dokter Fakultas Kedokteran Universitas Tanjungpura; 2013.

11. Preišegolavilittl E, Leskauskas D, Adomaitiene V. Associations of quality of sleep with lifestyle factors and profile of studies among Lithuanian students. Medicina (Kaunas). 2010;46(7):482-9.

12. Tarihoran SE. Hubungan pola tidur dengan prestasi belajar mahasiswa keperawatan di Universitas Advent Indonesia Bandung. Bandung: Universitas Advent Indonesia (UNAI); 2012. 
13. Intan $\mathrm{M}$. Hubungan kualitas tidur dengan tingkat prestasi belajar pada siswa boarding school di SMAN 10 Fajar Harapan Kota Banda Aceh. Banda Aceh: Fakultas Kedokteran Universitas Syiah Kuala; 2015.
14. Killgore WDS, William DS, Lipizzi EL, Kamimore GH, Balkin TJ. Caffein effects on risky decision making after 75 hours of sleep deprivation. Aviation, Space and Environmental Medicine. 2007;78:957-62. 